BNL-77335-2006

Formal Report

\title{
Hydrothermally Self-Advancing Hybrid Coatings for Mitigating Corrosion of Carbon Steel
}

\author{
Toshifumi Sugama
}

November 2006

\author{
Energy Science and Technology Department \\ Energy Resources Division \\ Brookhaven National Laboratory \\ P.O. Box 5000 \\ Upton, NY 11973-5000 \\ www.bnl.gov
}

Notice: This manuscript has been authored by employees of Brookhaven Science Associates, LLC under Contract No. DE-AC02-98CH10886 with the U.S. Department of Energy. The publisher by accepting the manuscript for publication acknowledges that the United States Government retains a non-exclusive, paid-up, irrevocable, world-wide license to publish or reproduce the published form of this manuscript, or allow others to do so, for United States Government purposes. 


\section{DISCLAIMER}

This report was prepared as an account of work sponsored by an agency of the United States Government. Neither the United States Government nor any agency thereof, nor any of their employees, nor any of their contractors, subcontractors, or their employees, makes any warranty, express or implied, or assumes any legal liability or responsibility for the accuracy, completeness, or any third party's use or the results of such use of any information, apparatus, product, or process disclosed, or represents that its use would not infringe privately owned rights. Reference herein to any specific commercial product, process, or service by trade name, trademark, manufacturer, or otherwise, does not necessarily constitute or imply its endorsement, recommendation, or favoring by the United States Government or any agency thereof or its contractors or subcontractors. The views and opinions of authors expressed herein do not necessarily state or reflect those of the United States Government or any agency thereof. 
Hydrothermally Self-advancing Hybrid Coatings for Mitigating Corrosion of Carbon Steel

\author{
Toshifumi Sugama \\ Energy Resources Division \\ Energy Science and Technology Department \\ Brookhaven National Laboratory \\ Upton, NY 11973
}

This manuscript, issued by DOE Office of Geothermal Technologies, has been authored by Brookhaven Science Associates, LLC under Contract No. DE-AC0298CH10886 with the U.S. Department of Energy. The United States Government retains, and publisher, by accepting the article for publication, acknowledges, a world-wide license to publish or reproduce the published form of this manuscript, or allow others to do so, for the United States Government purposes. 


\begin{abstract}
Hydrothermally self-advancing hybrid coatings were prepared by blending two starting materials, water-borne styrene acrylic latex (SAL) as the matrix and calcium aluminate cement (CAC) as the hydraulic filler, and then their usefulness was evaluated as the room temperature curable anti-corrosion coatings for carbon steel in $\mathrm{CO}_{2}$-laden geothermal environments at $250^{\circ} \mathrm{C}$. The following two major factors supported the self-improving mechanisms of the coating during its exposure in an autoclave: First was the formation of a high temperature stable polymer structure of Ca-complexed carboxylate groups containing SAL (Ca-CCG-SAL) due to hydrothermal reactions between SAL and CAC; second was the growth with continuing exposure time of crystalline calcite and boehmite phases coexisting with Ca-CCG-SAL. These two factors promoted the conversion of the porous microstructure in the non-autoclaved coating into a densified one after 7 days exposure. The densified microstructure not only considerably reduced the conductivity of corrosive ionic electrolytes through the coatings' layers, but also contributed to the excellent adherence of the coating to underlying steel' s surface that, in turn, retarded the cathodic oxygen reduction reaction at the corrosion site of steel. Such characteristics including the minimum uptake of corrosive electrolytes by the coating and the retardation of the cathodic corrosion reaction played an important role in inhibiting the corrosion of carbon steel in geothermal environments.
\end{abstract}




\section{Introduction}

One way to reduce capital investment and the expenses of operating and maintaining geothermal power plants with brine temperatures up to $250^{\circ} \mathrm{C}$ is to use inexpensive carbon steel components coated with cost-effective anticorrosion and antifouling materials instead of the very expensive stainless steel, titanium alloy, and inconel components that commonly are employed as a low corrosive metals. In this concept, the coatings play a pivotal role in extending the lifecycle of the carbons steel components, eventually lowering the costs of electricity generated from these plants.

The completion of some plant components, such as the heat-exchanger unit and long pipeline, requires joints. Roller-expansion and welding processes are among the most popular ways to make the heat exchanger ( $\mathrm{HX}$ ) tube-to-tube sheet joints, and also the pipe-to-pipe joints. In the former process, the thickness of the walls of the carbon steel HX tubes are reduced by $\sim 6 \%$ as they are rolled into a tube sheet. Currently, none of available coatings can withstand such high compressive strength and abrasive wear during this expansion. Likewise, welding at high temperature causes thermal decomposition of the coatings. Hence, the joint areas, of $\sim 10.0 \mathrm{~cm}$ wide, must be recoated in the factories or in the field with materials having the following four important properties: 1) good curability at temperatures up to $100^{\circ} \mathrm{C}$; 2) hydrothermal stability of > $200^{\circ} \mathrm{C}$; 3) good adherence to the joint areas; and, 4) be suitable for application with a paintbrush or spray gun. In addition, the material cost must be as low as possible.

In our two previous studies on the effectiveness of hydraulic cement-type fillers in enhancing the resistance of poly (phynelensulfide) (PPS) to abrasive wear [1], and in improving the hydrothermal stability of styrene/acrylonitril/trimethylopropane trimethacrylate and polyester/styrene copolymers [2-4], we incorporated an appropriate amount of calcium aluminate cement (CAC) and calcium silicate cement (CSC) into the PPS and copolymer, respectively. When this PPS/CAC coating system was exposed in a sulfuric acid-rich geothermal environment under high-brine temperatures and pressures, the CAC fillers present in the $65 \mu \mathrm{m}$ thick superficial layer reacted favorably with the sulfuric acid in the brine that permeated through the coating layer. This reaction generated well-formed boemite crystals known to be a hard, strong, engineering ceramic. 
Such in-situ growth of boehmite crystals co-existing with the PPS at the outermost surface sites significantly enhanced the coating's resistance to abrasive wear. In the copolymer/CSC system, the hydrothermal reaction between the Ca ions liberated from CSC filler and the ester groups in copolymer at $240^{\circ} \mathrm{C}$ led to the formation of Cacomplexed carboxylate compounds that were responsible for improving the hydrothermal stability of this copolymer.

On the other hand, a mixture of water-borne latex materials, such as the poly(vinyl acetate), polychloroprene, polymethacrylates, poly(vinyl choloride) and the copolymers of polystyrene, polybutadiene, and polyacrylonitirile, made by emulsion polymerization, is widely used in hydraulic cements to improve their mechanical properties, chemical resistance, and water proofing [5-10].

Based upon information described above, our particular interest is to assess the potential of mixed slurries of styrene acrylic latex and CAC filler as room temperaturecurable high temperature performance coatings for joint areas. Therefore, six factors were assessed: 1) Curing time of the slurries at room temperature; 2) conductivity of the corrosive ionic electrolytes through the coating layers; 3) identification of the hydrothermal reaction products between the latex and CAC, and of the crystalline phases yielded in the coating after exposure in $\mathrm{CO}_{2}$-laden water at $250^{\circ} \mathrm{C}$; 4) thermal stability of the hydrothermal reaction products; 5) adherence of the coating to the underlying steel; and, 6) corrosion-preventing performance of the coating layers covering the steel's surface.

\section{Experimental Procedure}

Materials

Noveon, Inc supplied the water-borne styrene acrylic latex (SAL, Trade Name, HYCA ${ }^{\circledR 26-1265) . ~ T a b l e ~} 1$ shows the general properties of this latex that is acid. Calcium aluminate cement (CAC, Secar 60) used as the hydraulic filler was obtained from the Lafarge Aluminate Corp. The CAC contained two major oxides, 69.8-72.2 \% aluminum oxide and 26.8-29.2 \% calcium oxide. The filler had a surface area of $3800-4400 \mathrm{~cm}^{2} / \mathrm{g}$, and a particle size of $<90 \mu \mathrm{m}$. An x-ray diffraction (XRD) analysis revealed that mineralogically it consisted of crystalline calcium monoaluminate $\left(\mathrm{CaO} . \mathrm{Al}_{2} \mathrm{O}_{3}, \mathrm{CA}\right)$ as 
the principal component, calcium dialuminate $\left(\mathrm{CaO} .2 \mathrm{Al}_{2} \mathrm{O}_{3}, \mathrm{CA}_{2}\right)$ as the secondary component, and pervoskite $\left(\mathrm{CaTiO}_{3}\right)$ as the minor one. The metallic substrate used was commercial AISI 1008 carbon steel. Five slurries made with SAL/CAC ratios of 100/0, $80 / 20,60 / 40,40 / 60$, and 30/70, by weight, were evaluated. The slurries were prepared in a shear-blender to uniformly distribute the CAC filler in the latex medium. In preparing the test samples, the slurries were directly painted on to the alkali-cleaned carbon steel coupons ( $65 \mathrm{~mm}$ x $65 \mathrm{~mm}$ ), and then left for 24 hours at room temperature to solidify the slurry. This coating process was repeated several times to obtain coating thicknesses ranging from 0.9 to $1.2 \mathrm{~mm}$. For comparison, CAC slurry made with a water/CAC ratio of 0.5 also was deposited on the steel's surface. The coated coupons then were exposed for up to 21 days in an autoclave containing $0.05 \mathrm{M} \mathrm{Na}_{2} \mathrm{CO}_{3}$-laden water at $250^{\circ} \mathrm{C}$.

\section{Measurements}

Using a contact angle analyzer, the extent of wettability and spreadability of water over the aged coating surfaces at room temperature was determined to assess the curing rate of the coating. For instance, when the coatings' surfaces were insufficiently cured, such as in the gel and sintering states, a water droplet from the analyzer had strong affinity with the non-reacted and non-volatilized water in the latex, thereby extending its wettability and spreadability. The contact angle was measured within the first $30 \mathrm{sec}$. after dropping the water onto the coated metal surfaces. To support the data above, the setting time of the coatings at room temperature was measured in accordance with the ASTM C 191-92 Standard test method for time of setting of hydraulic cement by Vicat needle. AC electrochemical impedance spectroscopy (EIS) was used to evaluate the ability of the exposed coating layers to protect the steel from corrosion. The specimens were mounted in a holder, and then inserted into an electrochemical cell. Computer programs were prepared to calculate theoretical impedance spectra and to analyze the experimental data. Specimens with a surface area of $13 \mathrm{~cm}^{2}$ were exposed to an aerated $0.5 \mathrm{M}$ sodium chloride electrolyte at $25^{\circ} \mathrm{C}$, and single-sine technology with an input $\mathrm{AC}$ voltage of $10 \mathrm{mV}$ (rms) was employed over a frequency range of $10 \mathrm{KHz}$ to $10^{-2} \mathrm{~Hz}$. To estimate the protective performance of the coatings, the pore resistance, $\mathrm{Rp},\left(\mathrm{ohm}-\mathrm{cm}^{2}\right)$ was determined from the plateau in Bode-plot scans that occurred in low frequency 
regions. The alteration in molecular structure of the styrene acrylic polymer (SAP) in the CAC after autoclaving was surveyed by Fourier transform infrared spectroscopy (FT-IR). The crystalline phases formed in the autoclaved coatings were identified by a combination of FT-IR and X-ray diffraction (XRD). Thermogravimetric analysis (TGA) gave the thermal decomposition temperature of bulk SAP and the SAP in CAC before and after exposure in $250^{\circ} \mathrm{C}$ autoclave. Scanning electron microscopy (SEM) coupled with energy-despersive X-ray spectrum (EDX) was used to explore the microstructure developed in the autoclaved coatings, and to reveal the morphological features of the underlying steel's surfaces after physically removing the autoclaved coating layers. DC electrochemical testing was employed to estimate the ability of the coating adhering to the underlying steel to protect the steel against corrosion. This test was performed with the EG\&G Princeton Applied Research Model 362-1 Corrosion Measurement System. The electrolyte was a $0.5 \mathrm{M}$ sodium chloride. The specimen was mounted in a holder, and then inserted into an EG\&G Model K47 electrochemical cell. The test was conducted under aerated conditions at $25^{\circ} \mathrm{C}$, on an exposed surface area of $1.0 \mathrm{~cm}^{2}$. The polarization curves were measured at a scan rate of $0.5 \mathrm{mVs}^{-1}$ in the corrosion potential range from 0.95 to $-0.20 \mathrm{~V}$.

\section{Results and discussion}

Curing of Slurries

Figure 1 plots the changes in contact angle, $\theta$, (in degrees) of the water dropped on the surfaces of coatings at room temperature as a function of curing time. Thirty minutes after the slurries were deposited on the surfaces of carbon steels, the value of the contact angle depended primarily on the proportion of SAL to CAC by weight; this value increased with a decrease in the SAL/CAC ratio. For instance, the contact angle of bulk SAL coating's surfaces without CAC rose $~ 10 \%$ when $20 \%$ of the total amount of SAL was replaced with CAC. Further replacement to $40 \%$ CAC enhanced its value by $18 \%$. The 30/70 ratio coating containing the highest content of CAC in this test series exhibited a high contact angle of $80.4^{\circ}$, which is equivalent to an increase of more than $35 \%$ compared with that of the bulk SAL surfaces. Since a low contact angle signifies a high extent of susceptibility of the coating's surface to moisture, this finding strongly 
suggested that incorporating CAC lowers the susceptibility of the SAL coating's surface to moisture. In other words, adding more CAC to the SAL, reflecting an increasing surface hydrophobicity, developed a good water-repellent coating.

The data also revealed that the $\theta$ value for all the coatings markedly increased with curing time between $30 \mathrm{~min}$ and $240 \mathrm{~min}$; beyond that, the increase was monotonous. Thus, the sensitivity of these coating surfaces to moisture is almost negative after leaving them for $240 \mathrm{~min}$ at room temperature, suggesting that these coating surfaces were almost completely cured by this time. No matter how much longer the coatings were left, no further changes were seen in the magnitude of water-repellency and -shedding from their surfaces made by varying the SAL/CAC ratios. Since the one key factor to improving the ability of the coatings to protect the metals against corrosion is the hydrophobicity of their surfaces, it is possible to assume that the coatings made with lower SAL/CAC ratios have minimum rates of water permeability and corrosive ion conductivity through their layers, compared to those made with higher ratios.

To support this information, the setting time of coatings at room temperature was measured in accordance with the ASTM C 191-92. This standard test was established to determine the time of setting of hydraulic cement by the Vicat needle. Thus, the coating slurries made with three different ratios, 30/70, 40/60, and 60/40, were employed in this test. The results showed that the slurries made with the 30/70 ratio set within as little as 100 min after mixing these two chemical components. The setting time of the 40/60 ratio slurries was $\sim 420$ min, corresponding to $~ 320$ min delay compared with that of the 30/70 ratio. Slurries with the 60/40 ratio exhibited a much delayed setting time of $\sim 1540$ min. Hence, the CAC hydraulic filler appears to promote the setting time of the SAL coatings.

\section{EIS Test}

One important factor affecting the mitigation of corrosion by the coatings is their conductivity of corrosive electrolytes; namely, the extent of uptake of electrolytes by the coatings plays a pivotal role in inhibiting or accelerating the corrosion of underlying steel. To obtain this information, coated coupons were exposed for up to 25 days in an autoclave at $250^{\circ} \mathrm{C}$. Unexposed and exposed coupons were mounted in a holder, and then 
inserted into a flat electrochemical cell. The coated coupons with a surface area of $13 \mathrm{~cm}^{2}$ were exposed to aerated $1.0 \mathrm{M}$ sodium chloride electrolyte at $25^{\circ} \mathrm{C}$ for $10 \mathrm{~min}$ before the EIS test.

Figure 2 compares the Bode-plot features [the absolute value of impedance $|\mathrm{Z}|\left(\mathrm{ohm}-\mathrm{cm}^{2}\right)$ vs. frequency (Hz)] of the coupons coated with 30/70 ratio before and after autoclaving. Particular attention in the overall EIS curve was given to the pore resistance, $R_{p}$, which can be determined from the peak in the Bode-plot occurring at sufficiently low frequency between $10^{-1}$ and $10^{-2} \mathrm{~Hz}$. For the unexposed coating, the $R_{p}$ value was $5.5 \times 10^{3} \mathrm{ohm}-\mathrm{cm}^{2}$. Interestingly, when this coating was autoclaved for 1 day, its value rose more than one order of magnitude to $8.2 \times 10^{4} \mathrm{ohm}-\mathrm{cm}^{2}$. Since the $R_{p}$ value reflects the extent of ionic conductivity generated by the $\mathrm{NaCl}$ electrolyte passing through the coating layers, such an increase represented a reduction in the uptake of electrolytes by the coating, as it was autoclaved. A considerable further reduction of uptake was observed after 7 days exposure, corresponding to an $R_{p}$ value of $3.5 \times 10^{9}$ ohm- $\mathrm{cm}^{2}$, which is nearly six orders of magnitude higher than that of the unexposed coating. However, prolonging the exposure to 21 days did not significantly increase this value. This finding strongly demonstrated that extended autoclave exposure entails a selfadvancement in the property of the coating in strikingly restraining the filtration of electrolytes through its layers. In other words, the coating's efficacy as corrosionpreventing barrier layer was markedly enhanced during exposure in an autoclave at $250^{\circ} \mathrm{C}$.

Figure 3 depicts the changes in $R_{p}$ value as a function of autoclave exposure time for these coated coupons. Before exposure, all the SAL/CAC coating systems, except for the 80/20 ratio one, had a higher $R_{p}$ value than that of the bulk SAL coating without CAC, suggesting that the CAC-filled SAL coatings display a better performance in resisting the transportation of corrosive electrolytes through their layers, compared with that of the bulk SAL coating. The data also showed that the magnitude of the uptake of electrolytes by coatings depended on the SAL/CAC ratio; adding more CAC to the SAL lowered its uptake. In fact, the $R_{p}$ value of the 30/70 ratio was tantamount to 1.3-, 4.2-, and 19.0-fold higher than those of the 40/60, 60/40, and 80/20 ratios, respectively. The 
bulk CAC reference coating without SAL has little, if any, ability to resist the transportation of electrolytes because of its $R_{p}$ value of less than a $100 \mathrm{ohm}-\mathrm{cm}^{2}$.

All the coatings exhibited an increase in $R_{p}$ value after the first day of exposure. Extending it to 7 days for three coating systems, bulk CAC, bulk SAL, and 80/20 ratio, caused a decline in this value; in particular, the rate of decline in bulk SAL was considerably higher. In contrast, the 7-day exposure increased this value in all coating systems; beyond that, between 7 and 21 days, there were no significant changes in this value, demonstrating that the maximum effectiveness of these self-advancing coatings in abating the extent of the conductivity of electrolytes is generated during these 7 days. Nevertheless, the $R_{p}$ values (ohm- $\mathrm{cm}^{2}$ ) of these 21-day exposure coatings were as follows; $6.1 \times 10^{9}$ for $30 / 70$ ratio, $1.6 \times 10^{9}$ for $40 / 60$ ratio, $3.6 \times 10^{4}$ for the $60 / 40$ ratio, $4.5 \times 10^{3}$ for the $80 / 20$ ratio, and $1.8 \times 10^{3}$ for the CAC, while the bulk SAL coating completely disintegrated during this exposure time. Thus, the most effective SAL/CAC ratio in mitigating the corrosion of underlying steel was 30/70. Correspondingly, adding an appropriate amount of CAC hydraulic filler appears to enhance significantly the hydrothermal stability of the SAL polymer, and to improve amazingly its suitability for use as a high hydrothermal temperature-performance coating.

\section{FT-IR and XRD Studies}

In response to the intriguing question of why the combination of SAL and CAC generates an unique coating system possessing self-advancing characteristics in mitigating the corrosion of steel in a $\mathrm{CO}_{2}$-laden hydrothermal environment, FT-IR and XRD analyses were carried out on the 30/70 ratio coatings before and after exposure for 2 hrs, 24 hrs, 7 days, and 21 days. Figure 4 gives the FT-IR spectra for these $100^{\circ} \mathrm{C}$ heated 30/70 ratio coatings over the frequency range from 4280 to $500 \mathrm{~cm}^{-1}$. The spectrum of the unexposed coating denoted as "O hr" had eight representative absorption bands: at 3439 and $1601 \mathrm{~cm}^{-1}$, corresponding to the O-H stretching and $\mathrm{H}-\mathrm{O}-\mathrm{H}$ bending vibrations, respectively, in water; at 2945 and $1164 \mathrm{~cm}^{-1}$ attributed to the $-\mathrm{CH}_{2}$ stretching vibration in SAL; at $1726 \mathrm{~cm}^{-1}$, revealing the $\mathrm{C}=\mathrm{O}$ stretching vibration in carboxylic acid $(\mathrm{COOH})$ groups; at $1450 \mathrm{~cm}^{-1}$, assigned to the $\mathrm{CO}_{3}{ }^{2-}$ in carbonated $\mathrm{CAC}$ filler; and, at 798 and $638 \mathrm{~cm}^{-1}$, belonging to the CAC. 
After autoclaving this coating for 2 hours at $250^{\circ} \mathrm{C}$, its spectral features differed markedly from those of the unexposed one; in particular, five new bands has appeared at 3295, 3086, 1560, 1412, and $1074 \mathrm{~cm}^{-1}$, and the COOH-related band at $1726 \mathrm{~cm}^{-1}$ had vanished. According to literature [11-13], the three new bands at 3295, 3086, and 1074 $\mathrm{cm}^{-1}$ are due to the formation of boehmite, $\gamma$ - $\mathrm{AlOOH}$, phase, and the new band at 1560 $\mathrm{cm}^{-1}$ is associated with the $\mathrm{C}=\mathrm{O}$ stretching vibration in carboxylate anion, $\mathrm{COO}^{-}$, groups, while the contributor to the new band at $1412 \mathrm{~cm}^{-1}$ is the $\mathrm{CO}_{3}{ }^{2-}$ in carbonated CAC. The formation of carboxylate anion in the coating can be interpreted as follows: As is well

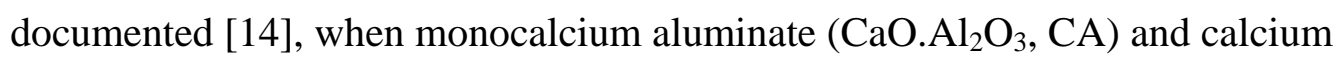
dialuminate $\left(\mathrm{CaO}_{2} 2 \mathrm{Al}_{2} \mathrm{O}_{3}, \mathrm{CA}_{2}\right)$ reactants in $\mathrm{CAC}$ fillers come in contact with water, three ionic species, $\mathrm{Ca}^{2+}, \mathrm{OH}^{-}$, and $\mathrm{Al}(\mathrm{OH})_{4}{ }^{-}$, are liberated from the surfaces of $\mathrm{CAC}$ fillers by their hydrolysis. Hence, the carboxylic acid groups within the SAL preferentially react with hydroxyl hydrolysate as the base reactant yielded near the hydrolyzed CAC surfaces. This acid-base reaction led to the in-situ transformation of carboxylic acid into the carboxylate anion derivative, $-\mathrm{COOH}+\mathrm{OH}^{-} \rightarrow-\mathrm{COO}^{-}+\mathrm{H}_{2} \mathrm{O}$. Then, the uptake of $\mathrm{COO}^{-}$by $\mathrm{Ca}^{2+}$ as its counter cation, aids in assembling the $\mathrm{Ca}$ complexed carboxylate structure as the reaction product, $2-\mathrm{COO}^{-}+\mathrm{Ca}^{2+} \rightarrow-\mathrm{COO}^{-} \mathrm{Ca}^{2+-}$ OOC-. Hence, most of carboxylic acid groups in SAL reacted hydrothermally with the $\mathrm{Ca}^{2+}$ and $\mathrm{OH}^{-}$hydrolysates during the first 2 hours of exposure. This is the major reason why the $\mathrm{COOH}$-associated band at $1726 \mathrm{~cm}^{-1}$ was eliminated after such a short-term exposure. Meanwhile, the remaining $\mathrm{Al}(\mathrm{OH})_{4}{ }^{-}$hydrolysate was transformed into boehmite, $\mathrm{Al}(\mathrm{OH})_{4}{ }^{-}+\mathrm{H}^{+} \rightarrow \mathrm{AlH}(\mathrm{OH})_{4} \rightarrow \gamma-\mathrm{AlOOH}+2 \mathrm{H}_{2} \mathrm{O}$.

In trying to identify the carbonated compounds and to support the above information, the same 2 hour-autoclaved coating as used in the FT-IR was analyzed by XRD over the diffraction range of 0.884 to $0.134 \mathrm{~nm}$. The resultant XRD pattern (not shown) revealed that two major crystalline phases, boehmite and calcite $\left(\mathrm{CaCO}_{3}\right)$, had been formed. Consequently, the carbonated compound was identified as calcite. The $\mathrm{Ca}^{2+}$ ions dissociated from the hydrolyzed CA and $\mathrm{CA}_{2}$ reactants in CAC not only reacted with SAL to form Ca-complexed carboxylate as the reaction product, but also had a strong affinity with $\mathrm{CO}_{3}{ }^{2-}$ in a hot $\mathrm{CO}_{2}$-laden water to yield calcite, $\mathrm{Ca}^{2+}+\mathrm{CO}_{3}{ }^{2-} \rightarrow \mathrm{CaCO}_{3}$. 
These two reactions resulted in destitution of $\mathrm{Ca}$ in the $\mathrm{CA}$ and $\mathrm{CA}_{2}$ reactants that was followed by the transition of the Ca-depleted reactants into the boehmite phase.

Returning to figure 4, prolonging the exposure time to 24 hours resulted in three conspicuous changes in the spectral features of the coating compared with that after 2 hours expose: First, the absorbance of all boehmite- related bands increased; second, the intensity of the calcite- related bands at 1450 and $1412 \mathrm{~cm}^{-1}$ strengthened, in conjunction with the emergence of another calcite- related band at $855 \mathrm{~cm}^{-1}$; and, third, there was a markedly decrease in absorbance of non-hydrolyzed CAC at 798 and $638 \mathrm{~cm}^{-1}$. Regarding the third finding, since these bands overlap those of boehmite [11], this finding, together with the first and second findings demonstrated that autoclaving for 24 hours leads to the incorporation of more crystalline boehmite into the coating because of the extended carbonating reaction between the $\mathrm{CA}$ or $\mathrm{CA}_{2}$ and $\mathrm{CO}_{3}{ }^{2-}$, while the shape of the prominent peak of Ca-complexed carboxylate-related band still remains unchanged.

After 7 days exposure, the spectrum showed that more calcite and boehmite phases were formed in the coating, as reflected in the striking increase in the intensity of these phase-associated bands. A further increase in their intensity was evident after 21 days, while there was no significant change in the peak intensity of Ca-complexed carboxylate band. Thus, the 21-day exposed coating was characterized by a hybrid structure containing three chemical components, a Ca-complexed carboxylate groupcontaining SAL (Ca-CCG-SAL) polymer, boehmite, and calcite; this combination appeared to minimize the rate of permeation of corrosive electrolytes through the coating, conferring the ability to act as a corrosion-preventing barrier layer for the underlying steel.

\section{TGA Study}

One critical issue in using SAL as a high-temperature performance coating is its hydrothermal stability at $250^{\circ} \mathrm{C}$. As described in the EIS study, the single SAL polymer coating without any hydraulic filler failed within 21 days autoclaving. It is very important to know the thermal stability of the Ca-CCG-SAL polymer coexisting with the boehmite and calcite phases. To obtain this information, three 30/70 ratio coatings, a nonautoclaved, and 2-hour and 21-day autoclaved ones, were investigated using TGA. All 
coatings were dried for 24 hours at $110^{\circ} \mathrm{C}$ to eliminate free moisture before TGA testing. Figure 5 depicts their TGA curves between $70^{\circ}$ and $800^{\circ} \mathrm{C}$. The curve of the nonautoclaved coating revealed that thermal decomposition of the SAL polymer began at $320^{\circ} \mathrm{C}$. The features of the curve of the 2-hour autoclaved coating highlighted a two-step decomposition process; the first phase took place at $\sim 70^{\circ} \mathrm{C}$; the second one was at $415^{\circ} \mathrm{C}$. The former represents the elimination of some $110^{\circ} \mathrm{C}$-irremovable moisture adsorbed in the coating, corresponding to a loss of nearly $2 \mathrm{wt} \%$ between $\sim 70^{\circ}$ and $~$ $415^{\circ} \mathrm{C}$. The second stage of decomposition was related directly to changes in the CaCCG-SAL polymer, and so the onset of this decomposition was $\sim 415^{\circ} \mathrm{C}$, which is $~$ $95^{\circ} \mathrm{C}$ higher than that of the bulk SAL polymer. This finding strongly demonstrated that the thermal stability of the SAL polymer was significantly enhanced as its structure was transformed into that of Ca-CCG-SAL polymer by the hydrothermal reaction between CAC and SAL. Thus, this transformation played an important role in improving the corrosion-preventing performance of the $250^{\circ} \mathrm{C}$ - autoclaved coating. The 21-day autoclaved coating exhibited similar feature, except for one additional stage of decomposition at a temperature of $\sim 647^{\circ} \mathrm{C}$; thus, the first and second thermal decompositions that began at $\sim 70^{\circ}$ and $\sim 415^{\circ} \mathrm{C}$ were attributed, respectively, to the elimination of moisture and the degradation of Ca-CCG-SAL, while this new phase of decomposition was associated with the disintegration of calcite [15], $\mathrm{CaCO}_{3} \rightarrow \mathrm{CaO}+$ $\mathrm{CO}_{2} \uparrow$. Consequently, although this was a short-term autoclave test of 21 days, the CaCCG-SAL polymer in the coating withstood a $250^{\circ} \mathrm{C}$ hydrothermal temperature. Its enhanced hydrothermal stability is one of the physicochemical factors contributing to the self-advancing characteristics of the hydride coating.

\section{SEM-EDX Exploration}

In seeking other physicochemical factors, the fractured surfaces of the nonautoclaved and 21-day autoclaved 30/70 ratio coatings were explored by SEM coupled with EDX. Figure 6 compares their SEM images. The image of the non-autoclaved coating revealed the presence of several deep voids, ranging in size from $\sim 42$ to $\sim 170$ $\mu \mathrm{m}$. In contrast, although the voids still remained in the layers, the image of 21-day 
autoclaved coating showed that these voids had become much shallower. Figure 7 shows a close-examination of a shallow cavity by SEM-EDX. The EDX spectrum taken from inside the cavity had two prominent elemental peaks, $\mathrm{Al}$ and $\mathrm{Ca}$, and two weak ones associated with the $\mathrm{C}$ and $\mathrm{O}$ elements. Relating this finding to those from FT-IR and $\mathrm{XRD}$ studies, it is possible to explicate that these two elements, $\mathrm{Al}$ and $\mathrm{O}$, are related to the crystalline boehmite, and the remaining two elements, $\mathrm{Ca}$ and $\mathrm{C}$, in conjunction with some O, are associated with crystalline calcite. Also, C would originate from Ca-CCGSAL. If this interpretation is valid, the original voids present in the coating seem to be filled by these crystalline phases during autoclaving. Thus, the filling of the cavities by the growth of these crystalline phases can be taken as another factor contributing to the self-advancing characteristics of hybrid coatings because of the in-situ conversion of a porous structure in the layers into a densified one.

\section{Adhesion}

Good adherence of the coating to the steel's surfaces is one of the pivotal factors affording adequate protection of steel against corrosion. If adherence is poor, the interfacial steel surface would be directly attacked by the corrosive reactants, such as oxygen, water, electrolytes, and gases, that permeate through the coating layers, thereby promoting the rate of its corrosion. Excessive corrosion of the steel beneath the coating then generates undesirable internal stress at interfaces, causing the blistering- and cracking-associated failure of the coatings. Thus, it is very important to have information on how well the hybrid coating adheres to the steel, and also on its corrosion-preventing performance. Figure 8 shows the morphological features of the interfacial steel surfaces after physically removing the 21-day autoclaved 30/70 ratio coating at the coating/steel joints, then blasted the surfaces with air compressed at $0.7 \mathrm{MPa}$. The SEM image revealed a very rough texture, representing the remnants of coating clinging to the steel's surfaces. This finding strongly demonstrated that the disbandment at the interfaces between the coating and steel took place in the coating layer, reflecting an ideal cohesive bond-failure mode. In other words, the bond strength developed at the interfaces was greater than the strength of the coating itself, verifying the outstanding adherence of the coating to the steel's surfaces. 
Attention now shifted to investigating the efficacy of these strongly adhering remnants of the hybrid coating in protecting the steel's surfaces against corrosion. To obtain this information, the steel panel covered with the coatings' remnants was examined by DC potentiodynamic polarization test; the bare steel without any coating was used as the control. Figure 9 gives the typical cathodic-anodic polarization curves plotting the polarization voltage, $E$, versus current density, $\mathrm{A} / \mathrm{cm} 2$, for these steel panels. The shape of the curves shows the transition from cathodic polarization at the onset of the most negative potential to the anodic polarization curves at the end of positive potential. The potential axis at the transition point from cathodic to anodic curves is normalized as the corrosion potential, $E_{\text {corr }}$. The curve from steel panel with remnants showed two noticeable differences from the bare one: First was a shift in the Ecorr value to a more positive site, and second was an decline of cathodic current density $\left(\mathrm{A} / \mathrm{cm}^{2}\right)$ at the starting point of the cathodic curve. Difference (1) directly reflects the extent of coverage of the coating over the steel's surface; namely, good coverage by a continuous void-free coating layer is responsible for moving the $E_{c o r r}$ value to a more positive site. Hence, the resulting shift to positive site of $E_{\text {corr }}$ demonstrated a good coverage of coatings' remnants over the steel's surface. For difference (2), the low value of the cathodic current density signifies that cathodic reaction at the corrosion site of steel is inhibited, particularly the oxygen reduction reaction, $2 \mathrm{H}_{2} \mathrm{O}+\mathrm{O}_{2}+4 \mathrm{e}^{-} \rightarrow 4 \mathrm{OH}^{-}$. Hence, the coating's remnants adhering to the steel's surface appears to retard this reaction that promotes the rate of corrosion of steel.

On the basis of these potentiodynamic polarization curves, the absolute corrosion rates of steel, expressed in the conventional engineering units of milli-inches per year (mpy) was determined. Eq. (1) proposed by Sterm and Geary[16], was used in the first step:

$I_{\text {corr }}=\beta_{a} \cdot \beta_{c} / 2.303\left(\beta_{a}+\beta_{c}\right) R_{p}$

where $I_{\text {corr }}$ is the corrosion current density in $\mathrm{A} / \mathrm{cm}^{2}, \beta_{a}$ and $\beta_{c}$ having the units of V/decade of current refer to the anodic and cathodic Tafel slopes, respectively, which were obtained from the $\log I$ vs. E plots encompassing both anodic and cathodic regions, and $R_{p}$ is the polarization resistance which was determined from the corrosion potential, 
$E_{\text {corr }}$ When $I_{\text {corr }}$ was computed through Eq. (1), the corrosion rate (mpy) can be obtained from the following expression:

Corrosion rate $=0.13 I_{\text {corr }}(E W) / d$

where $E W$ is the equivalent weight of the corroding species in g, and $d$ is the density of the corroding species in $\mathrm{g} / \mathrm{cm}^{3}$.

The results of the $I_{\text {corr }}$ and corrosion rate obtained from this Tafel calculation for uncovered steel panels and panels covered with the coatings' remnants were as follows: The corrosion rate of the bare steel was 8.98 milli-inches per year (mpy) accompanying $I$ corr of $1.92 \times 10^{-5} \mathrm{~A} / \mathrm{cm}^{2}$. These values fell when the steel' s surface was covered with the coating's remnants; in fact, the $0.87 \mathrm{mpy}$ and $1.90 \times 10^{-6} \mathrm{~A} / \mathrm{cm}^{2}$ obtained for the covered steel corresponded to a reduction of nearly one order of magnitude, compared with those of bare steel. This finding strongly demonstrated that the excellent adherence of the autoclaved 30/70 ratio coating to steel played a pivotal role in mitigating the corrosion of the underlying steel.

\section{Conclusions}

When water-borne styrene acrylic latex (SAL) was mixed with the calcium aluminate cement as hydraulic filler at room temperature, the setting time of SAL depended on the content of CAC; namely, an increase in its content shortened the pot-life of SAL. For instance, the setting time of the slurry made with the SAL/CAC ratio of 30/70 by weight, which was the highest content of CAC in this test series, was only a 100 min after mixing these two components. The decreasing content of CAC, as in the 40/60 ratio slurry, extended setting time to $\sim 420 \mathrm{~min}$, corresponding to $\sim 320$ min delay compared with that of the 30/70 ratio. Among the 100/0, 80/20, 60/40, 40/60, and 30/70 ratios, the surface of the slurry made with the 30/70 ratio was converted into the solid state within $240 \mathrm{~min}$ at room temperature. This mixture exhibited the lowest magnitude of susceptibility to moisture, suggesting that the surface of the SAL coating became more hydrophobic as the content of CAC was increased.

In the $\mathrm{CO}_{2}$-laden hydrothermal environment at $250^{\circ} \mathrm{C}$, the carboxylic acid, $\mathrm{COOH}$, groups within SAL hydrothermally reacted with the $\mathrm{Ca}^{2+}$ and $\mathrm{OH}^{-}$ions dissociated from the hydrolysis of CAC to form the Ca-complexed carboxylate group- 
containing SAL (Ca-CCG-SAL). Concurrently, the reaction between $\mathrm{Ca}^{2+}$ and $\mathrm{CO}_{3}{ }^{2-}$ led to the formation of crystalline calcite, $\mathrm{CaCO}_{3}$. These two reactions caused the depletion of $\mathrm{Ca}$ in the two calcium aluminate reactants in the CAC, calcium monoaluminate $\left(\mathrm{CaO} . \mathrm{Al}_{2} \mathrm{O}_{3}, \mathrm{CA}\right)$ and calcium dialuminate $\left(\mathrm{CaO} .2 \mathrm{Al}_{2} \mathrm{O}_{3}, \mathrm{CA}_{2}\right)$. The Ca-destitute CA and $\mathrm{CA}_{2}$ then were transformed into crystalline boehmite, $\gamma$-AlOOH. The carboxylic acid $\rightarrow$ Ca-complexed carboxylate group transition was completed in the first two hours of autoclave exposure. In contrast, the $\mathrm{CaCO}_{3}$ and beohmite crystals grew continuously throughout a 21-day autoclaving period.

The slurry made with 30/70 ratio displayed a great potential as a room temperature-curable anti-corrosion coating for heat exchanger/sheets and pipe/pipe joints. The following three major factors of this coating contributed significantly to mitigating the corrosion of carbon steel in $\mathrm{CO}_{2}$-laden geothermal environment at temperatures up to $250^{\circ} \mathrm{C}$ : First was the enhancement of the thermal stability of bulk SAL from $320^{\circ} \mathrm{C}$ to $415^{\circ} \mathrm{C}$ by its transformation into the Ca-CCG-SAL polymer; second was the conversion of the porous structure in the non-autoclaved coating into the densified one due to the growth of crystalline calcite and boemite with increasing autoclave time; and, third was its good adherence to the steel's surface. The integrity of these three factors provided a minimum uptake of corrosive electrolytes by the coating and the inhibition of the cathodic oxygen reduction reaction at the corrosion site of steel. In the former, the extent of corrosive ionic conductivity through the coating layer was considerably reduced as the autoclaving time was extended. This fact strongly demonstrated that this SAL/CAC hybrid coating system has a self-advancing characteristic that enhances its ability to protect the steel against corrosion during autoclaving.

\section{References}

1. T. Sugama and P. Hayenga, "Boehmite-reinforced Poly(phenylene sulfide) as a Wear/Corrosion Resistant Coating,” Poly. Poly. Comp., 8, (2000) 307-318.

2. T. Sugama, L.E. Kukacka, and W. Horn, "Hydrothermal Stability of VinylType Polymer Concrete Containing Tricalcium Silicate,” Cem. Conc. Res., 9, (1979) 461-471. 
3. T. Sugama, L. E. Kukacka and W. Horn, "Hydraulic Cement-type Fillers for Hydrotheramly Stable Polymer Concretes,” J. Mater. Sci., 15, (1980) 14981508.

4. T. Sugama, L. E. Kukacka and W. Horn, "Hydrothermal Durability of Capolyester Complexed Polymer Concrete,” Cem. Conc. Res., 11, (1981) 429442.

5. Y. Ohama, "Principle of Latex Modification and Some Typical Properties of Latex-Modified Mortars and Concretes,” ACI Mater. J., 84, (1987) 511-518.

6. L.M. Saija, "Waterproofing of Portland Cement Mortars with a Specially Designed Polyacrylic Latex,” Cem. Conc. Res., 25, (1995) 503-509.

7. J. Monteny, N. De Belie, E. Vincke, W. Verstaete, and L. Taerwe, “Chemical and Microbiological Tests to Simulate Sulfuric Acid Corrosion of Polymermodified Concrete,” Cem. Con. Res., 31, (2001) 1359-1365.

8. G. Xiong, X. Chen, G. Li, and L. Chan, "Sulphuric Acid Resistance of Soluble Soda Glass-Polyvinyl Acetate Latex-Modified Cement Mortar,” Cem. Con. Res., 31, (2001) 83-86.

9. R. Wang, P-M Wang, X-G Li, "Physical and Mechanical Properties of Styrene-butadiene Rubber Emulsion Modified Cement Mortars,” Cem. Conc. Res., 35, (2005) 900-906.

10. A. Colak, "Properties of Plain and Latex Modified Portland Cement Pastes and Concretes with and without Superplasticizer,” Cem. Conc. Res., 35, (2005) 1510-1521.

11. G. Krishina Priya, P. Padmaja, K.G.K. Warrier, A.D. Damodaran, and G. Aruldhas, "Dehydroxylation and High Temperature Phase Formation in Solgel Boehmite Characterized by Fourier Transform Infrared Spectroscopy,” J. Mater. Sci. Lett., 16, (1997) 1584-1587.

12. T. Takamori, M.W. Shafer, K.G. Frase, "Non-hydraulic Processing of Cements,” Cem. Conc. Res., 18, (1988) 479-484.

13. M. Nagai, T. Saeki, and T. Nishno, “Carbon Dioxide Sensor Mechanism of Porous Hydroxyapatite Ceramic,” J. Am. Ceram. Soc., 73, (1990) 1456-1460. 
14. E.J. Reardon, “An Ion Interaction Model for the Determination of Chemical Equilibria in Cement/Water Systems,” Cem. Conc. Res., 20, (1990) 175-192.

15. W. WM. Wendlandt, "Thermal Methods of Analysis," Second Edition, John Wiley \& Sons, (1974), p. 16.

16. M. Sterm and A.L. Geary, "Electrochemical Polarization I. A Theoretical Analysis of the Shape of Polarization Curves,” J. Electrochem. Soc., 104. (1975) 56-62. 


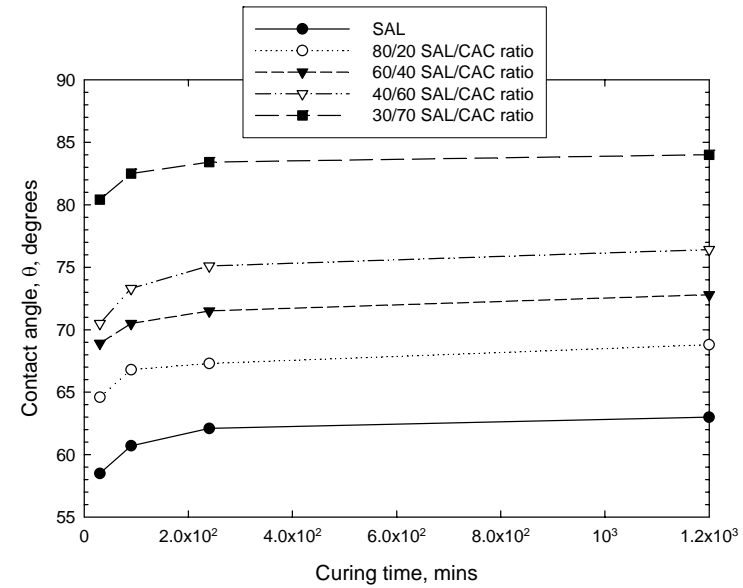

Figure 1. Changes in contact angle made by a water droplet on bulk SAL, and SAL/CAC ratio coatings of $80 / 20,60 / 40,40 / 60$, and $30 / 70$ as a function of curing time.

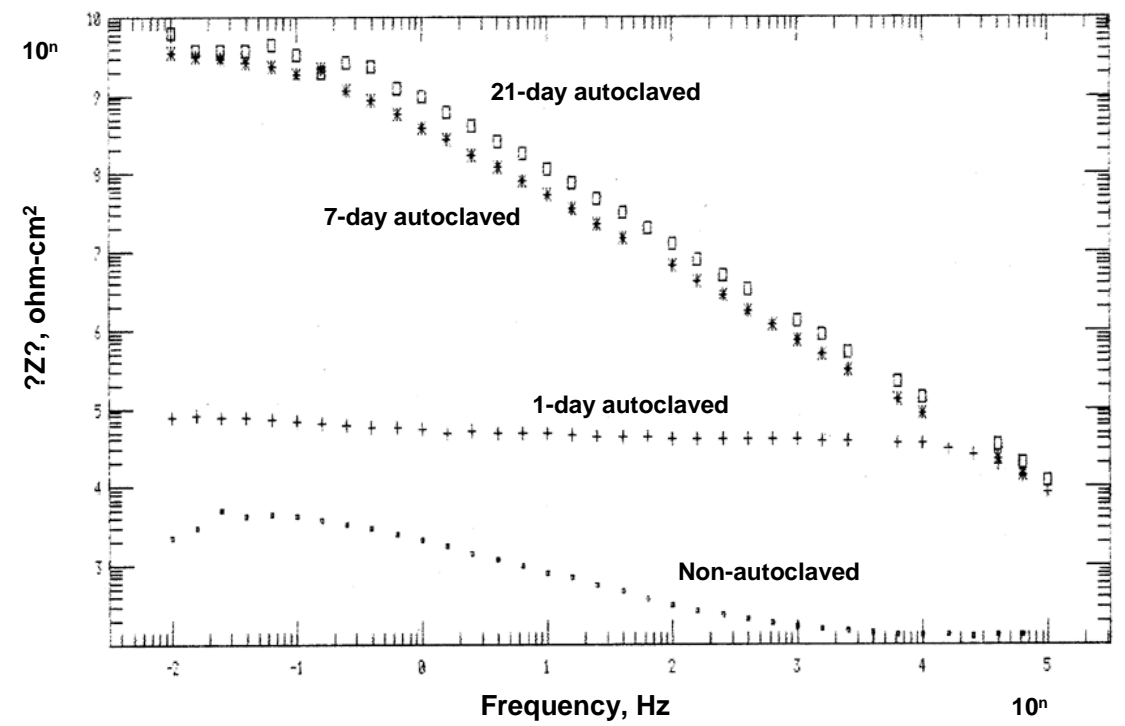

Figure 2. AC electrochemical impedance curves for non-autoclaved, and 1-, 7-, and 21-day autoclaved SAL/CAC 30/70 ratio coatings. 


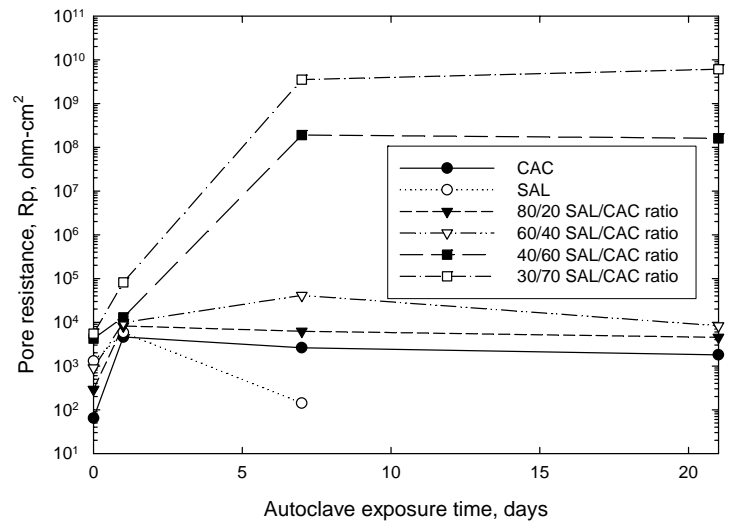

Figure 3. Pore resistance, $\mathrm{Rp}$, of various coatings plotted as a function of autoclaving time.

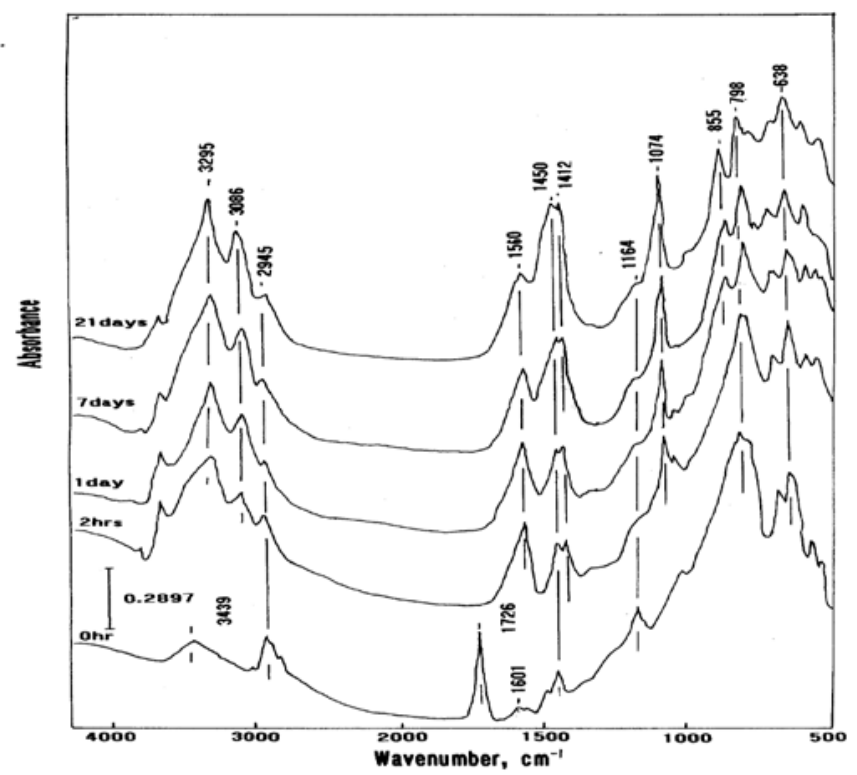

Figure 4. Comparison of FT-IR spectral features for non-autoclaved, and 2-hr, 1-, 7-, and 21-day autoclaved $30 / 70$ ratio coatings. 


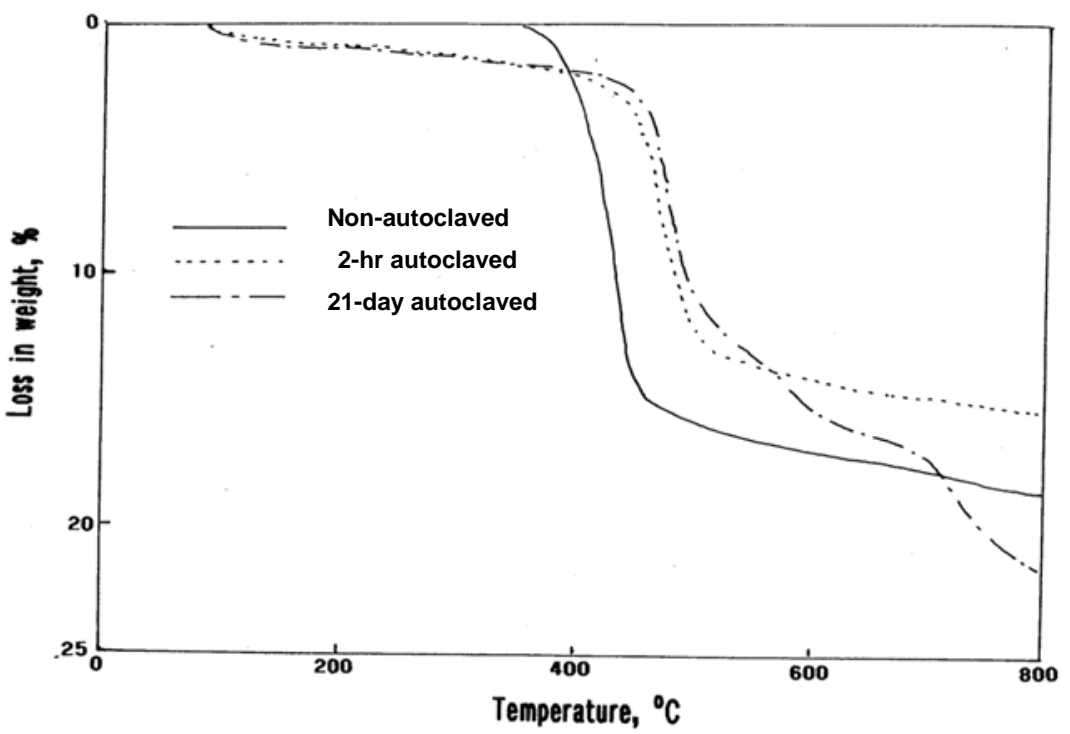

Figure 5. TGA curves of non-autoclaved, and 2-hr and 21-day autoclaved 30/70 ratio coatings.
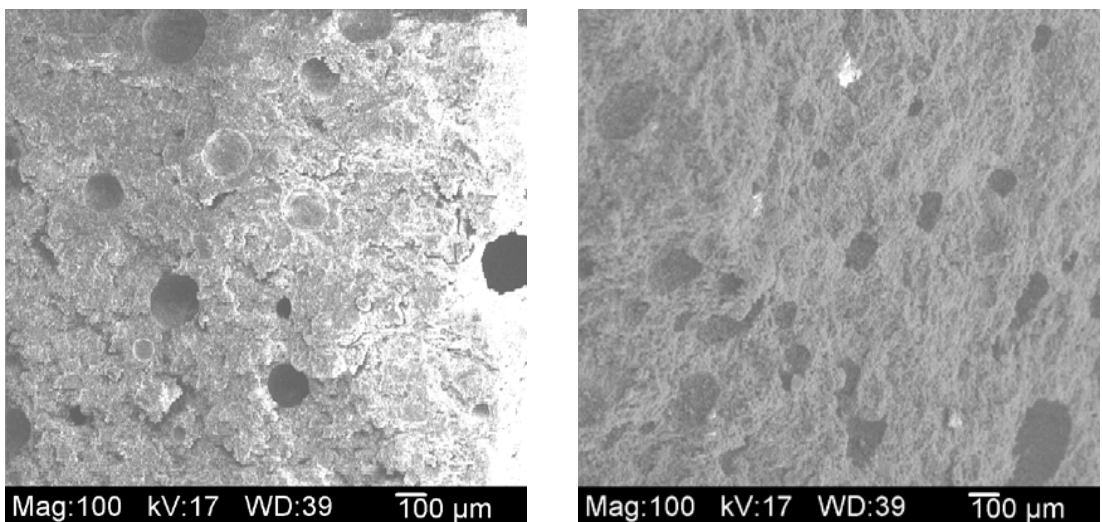

Figure 6. SEM images of fractured surfaces for non-autoclaved (left) and 21-day autoclaved (right) 30/70 ratio coatings. 

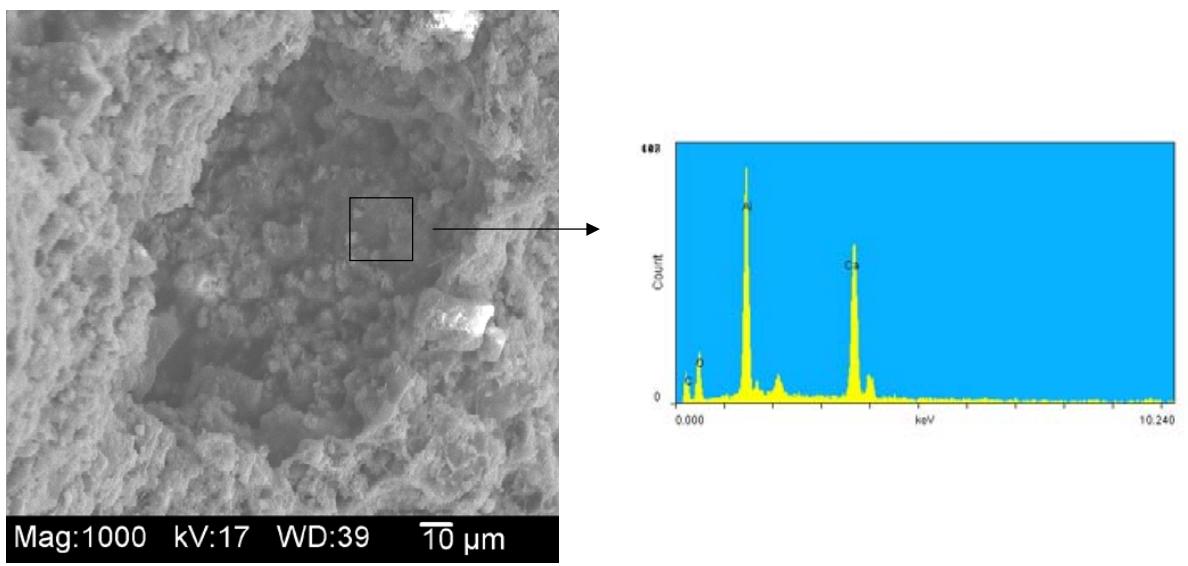

Mag:1000 kV:17 WD:39 $\overline{10} \mu \mathrm{m}$

Figure 7. SEM-EDX close-examination of shallow void filled by crystalline phases in 21-day autoclaved $30 / 70$ ratio coating

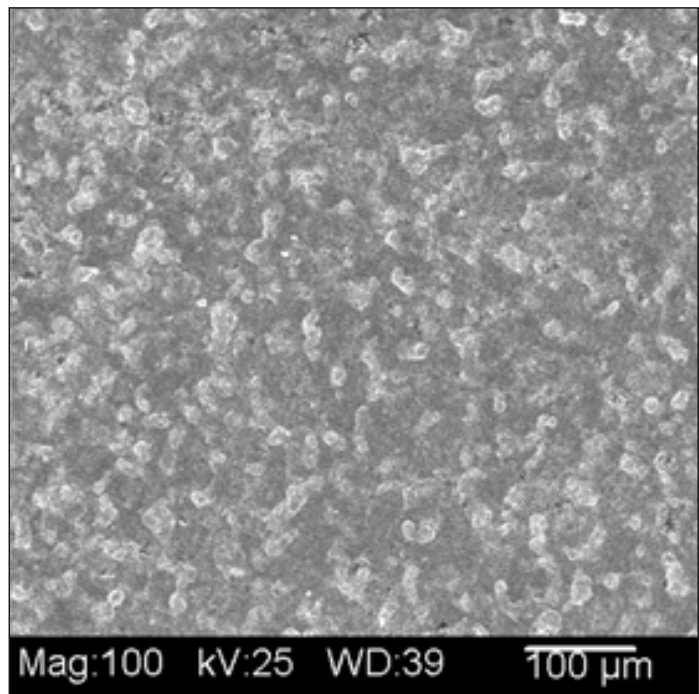

Figure 8. SEM image of interfacial steel site after physically removing the 21-day autoclaved 30/70 ratio coating. 


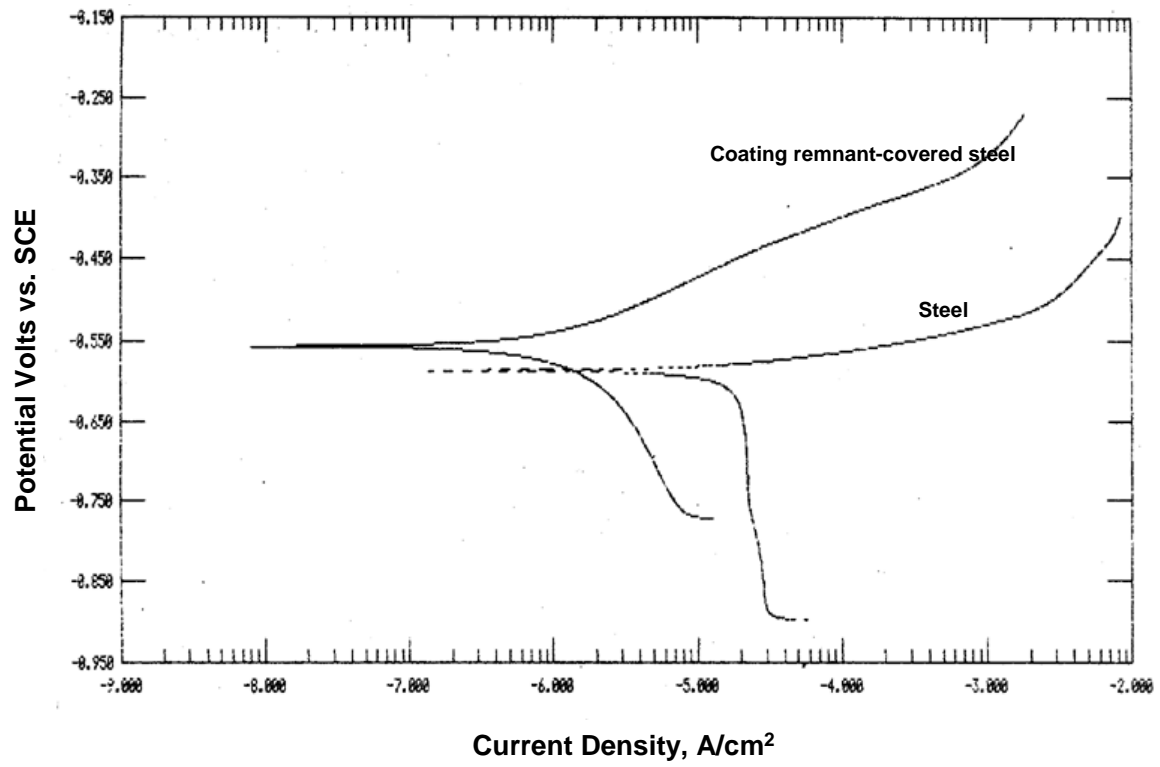

Figure 9. Potentiodynamic cathodic-anodic polarization diagrams for a bare steel, and steel covered with remnants of 21-day autoclaved $30 / 70$ ratio coating. 